\title{
Pre-radiotherapy PSA Level as a Predictor for Biochemical Control in Prostate Cancer Patients Receiving Radiotherapy after Radical Prostatectomy
}

\author{
Din-Li Tsan ${ }^{1}$, Kang-Hsing Fan ${ }^{1}$, Yen-Chao Chen ${ }^{1}$, Cheng-Keng Chuang ${ }^{2}$, \\ Chung-Chi Lee ${ }^{3}$, Ji-Hong Hong ${ }^{1}$
}

Background: To report the outcome of patients receiving radiotherapy (RT) after radical prostatectomy (RP).

Methods: Between May 2001 and December 2008, 53 consecutive cases of prostate adenocarcinoma treated with RP and RT were reviewed.

Results: $\quad$ A total of 49 patients were eligible for this study. After a median follow-up of 53 months, the 4-year overall survival (OS) and biochemical progression-free survival (bPFS) for all patients were $91.0 \%$ and $68.9 \%$, respectively. According to univariate and multivariate analysis, pre-RT prostate-specific antigen (PSA) was the most significant factor for bPFS. Patients with pre-RT PSA levels of $<0.2 \mathrm{ng} / \mathrm{ml}$ and $\geqq 0.2 \mathrm{ng} / \mathrm{ml}$ had a 4 -year bPFS of $83.1 \%$ and $52.6 \%$, respectively $(p=0.013)$. The incidence of chronic rectal toxicity was low, with no grade 3 toxicity reported and grade 2 toxicity found in only 6 patients $(12.2 \%)$. However, long-term urinary toxicity of grade 2 or higher was found in 24 patients $(49.0 \%)$.
At a Glance Commentary

Scientific background of the subject

Prostate cancer is the leading cancer of men in developed countries, and is rapidly increasing in other parts of the world. Radical prostatectomy is the main primary treatment for non-metastatic prostate cancer in Taiwan. However, some patients still need radiotherapy either as adjuvant or salvage treatment.

\section{What this study adds to the field}

This study showed that for patients with increasing PSA levels following radical prostatectomy, local radiotherapy should be administered prior to biochemical failure (PSA $\geqq 0.2 \mathrm{ng} / \mathrm{ml}$ ), for better control.

Conclusion: For patients with increasing PSA levels following RP, local RT should be administered prior to biochemical failure (PSA $\geqq 0.2$ ), to ensure good bPFS.

(Biomed J 2013;36:71-76)

Key words: adjuvant radiotherapy, complications, prostate cancer, radical prostatectomy, salvage radiotherapy

$\mathrm{I}$ n 2007, prostate cancer was the fifth ranked cancer among males in Taiwan, with a crude incidence of 29 per $100,000,{ }^{[1]}$ equivalent to one-fourth and one-sixth of that of the United Kingdom and the United States, respectively. ${ }^{[2,3]}$ Most patients in the United States are diagnosed in the early stages of the disease $;{ }^{[3]}$ however, in Taiwan, more than 50\% of cases are identified in stages T3-4 or with metastatic disease..$^{[4,5]}$ In a study of radical prostatectomy (RP) in three medical centers in Taiwan, it was discovered that Taiwanese patients were older at the time of surgery and exhibited higher pre-operative prostate-specific antigen (PSA) levels and biochemical failure rates than those reported in studies in the west. ${ }^{[6]}$ Similar findings were reported in another independent study, indicating that Taiwanese prostate cancer patients treated with RP also tended toward an advanced pathological stage, high Gleason scores, and high positive surgical margin rates. ${ }^{[7]}$ Similar findings have also been reported in other Asian countries. ${ }^{[8,9]}$ These results suggest that the use of radiotherapy (RT) for adjuvant or salvage treatment in high-risk prostate cancer patients following

From the ${ }^{1}$ Department of Radiation Oncology, Chang Gung Memorial Hospital at Linkou, Chang Gung University College of Medicine, Taoyuan, Taiwan, ${ }^{2}$ Department of Urology, Chang Gung Memorial Hospital at Linkou, Chang Gung University College of Medicine, Taoyuan, Taiwan, ${ }^{3}$ Department of Medical Imaging and Radiological Science, College of Medicine, Chang Gung University, Taoyuan, Taiwan Received: Mar. 13, 2012; Accepted: Jun. 13, 2012

Correspondence to: Dr. Ji-Hong Hong, Department of Radiation Oncology, Chang Gung Memorial Hospital. 5, Fusing St., Gueishan, Taoyuan 333, Taiwan (R.O.C.). Tel: 886-3-3281200 ext. 2601; Fax: 886-3-3280797; E-mail: jihong@cgmh.org.tw

DOI: $10.4103 / 2319-4170.110402$ 
RP might has a more significant impact in Asian countries, including Taiwan, than it does in the west.

Three large randomized studies, SWOG 8794, ${ }^{[10,11]}$ EORTC 22911,,$^{[12]}$ and German ARO 96-02,, ${ }^{[13]}$ all demonstrated the benefits of post-RP RT for high-risk patients to improve biochemical progression-free survival (bPFS), and even overall survival (OS) in selected categories. Adjuvant post-RP RT improved the 5-year bPFS from approximately 50-70\%. ${ }^{[12,13]}$ However, 6-year biochemical control by salvage radiation alone for patients with PSA $\geqq 0.2 \mathrm{ng} / \mathrm{ml}$ (a cut-off value for definition of postoperative biochemical failure) was only $32 \% .{ }^{[14]}$ Several studies have reported that the addition of androgen deprivation therapy (ADT) to post-RP RT is beneficial to bPFS. ${ }^{[15-17]}$ Considering the side effects caused by long-term ADT, further stratification of patients into different risk groups would no doubt facilitate the selection of high-risk patients for ADT.

Prostate cancer patients in Taiwan and other Asian countries are more likely to exhibit indicators for adjuvant or salvage RT following RP; therefore, the aim of this study was to evaluate the outcome of patients receiving adjuvant or salvage RT, and to identify those patients with an elevated risk of biochemical failure following RT.

\section{METHODS}

Between May 2001 and December 2008, we reviewed 53 consecutive cases of non-metastatic prostate adenocarcinoma treated with RP followed by RT. Three patients who had been receiving ADT for more than 6 months prior to RT and another patient without pathologic T stage were excluded from the study. Indicators for post-RP RT included pathological risk factors, such as extracapsular extension (ECE), seminal vesicle invasion (SVI), positive resection margin, positive lymph node (LN), increase in detectable PSA levels in at least two subsequent measurements, and biochemical and/or clinical failure. Post-RP biochemical failure was defined as a PSA level $\geqq 0.2 \mathrm{ng} / \mathrm{ml}$. Clinical failure was recorded by imaging and proven through pathological analysis.

Doses of RT ranged between 63 and $66.6 \mathrm{~Gy}$ for patients receiving adjuvant $\mathrm{RT}$ or those not presenting with gross lesions in pre-RT magnetic resonance imaging (MRI) or computed tomography (CT) scans, and 72 Gy for patients with gross tumors. RT was administered at $1.8 \mathrm{~Gy} / \mathrm{per}$ fraction/day and five fractions per week. The planning target volume (PTV) was generated with a posterior margin of $0.7 \mathrm{~cm}$ and with $1 \mathrm{~cm}$ margin in all other directions. The radiation to the prostate region was given by intensity-modulated radiotherapy (IMRT), but three-dimensional four-field (anterior-posterior and bilateral opposing) was applied to pelvic irradiation. Pelvic irradiation was administered to patients with $\mathrm{N} 1$ disease or $\geqq 15 \%$ pelvic $\mathrm{LN}$ metastasis rate accord- ing to the Roach formula of [2/3 PSA + (Gleason score -6$) \times$ 10]. ${ }^{[18]}$ Pelvic RT was omitted for pathological N0 cases, for patients older than 75 years, and for those with severe co-morbidity. ADT was permitted but not standardized.

Follow-up was conducted mainly by serum PSA testing and digital rectal examination (DRE), with imaging studies arranged when necessary. PSA was checked on the day at which RT was completed, and every 3-4 months for the first 2 years, continuing every 4-6 months thereafter. Acute and late adverse events were recorded at each visit to out-patient departments (OPD), focusing mainly on rectal and urinary toxicity. Adverse events persisting for more than 3 months after RT or appearing 3 months after completion of RT were defined as late events. The severity of adverse rectal and urinary events was recorded according to the Common Terminology Criteria for Adverse Events 3.0 (CTCAE 3.0), published by the Cancer Treatment Evaluation Program of the National Cancer Institute (CTEP/NCI).

The primary endpoints for evaluation were the relapse of disease in any form. Survival was measured from the last day of RT using Kaplan-Meier survival calculations. The bPFS time was calculated as the period between the last day of RT and the date of biochemical failure, which was defined as a PSA level $\geqq 0.2 \mathrm{ng} / \mathrm{ml}$. The log-rank test was used to determine differences in univariate analysis. Cox proportional-hazards regression analysis was employed in multiple covariate analysis. SPSS for Windows (version 13.0; SPSS Inc., Chicago, IL, USA) was used for all data analyses. The study was approved by the Institutional Review Board of the Chang Gung Memorial Hospital (99-3646B).

\section{RESULTS}

A total of 49 patients were eligible for this study, with a median age of 66 years. Median time from RP to RT was 5 months (range 1-71 months). Patient characteristics and distribution of pathologic prognostics are shown in Table 1. The median RT dose was 66.6 Gy. Twenty-five (51.0\%) patients underwent pelvic irradiation. The percentage of patients without ADT, with short-term ( $\leqq 6$ months) ADT, and with long-term ( $>6$ months, or orchiectomy) ADT was $53.1 \%, 20.4 \%$, and $26.5 \%$, respectively. Among the patients with pre-RT PSA $\geqq 0.2,39.1 \%$ had undergone long-term ADT; the corresponding figure was $14.3 \%$ for patients with pre-RT PSA $<0.2 \mathrm{ng} / \mathrm{ml}$.

After a median follow-up of 53 months (range 14-111 months), the 4-year OS and bPFS for all patients were $91.0 \%$ and $68.9 \%$, respectively [Figure 1]. Five patients died during the follow-up period, two of whom died of prostate cancer with distant metastases. According to univariate and multivariate analysis, pre-RT PSA was the most significant factor for bPFS [Table 2]. Patients with pre-RT PSA levels of $<0.2 \mathrm{ng} / \mathrm{ml}$ and $\geqq 0.2 \mathrm{ng} / \mathrm{ml} \mathrm{had} \mathrm{a} 4$-year bPFS 
Table 1: Patient characteristics $(n=49)$

\begin{tabular}{|c|c|}
\hline Median age (range) & 66 years old (53-76) \\
\hline \multicolumn{2}{|l|}{ Gleason score } \\
\hline $2-6$ & $11(22.4 \%)$ \\
\hline 7 & $16(32.7 \%)$ \\
\hline $8-10$ & $22(44.9 \%)$ \\
\hline \multicolumn{2}{|l|}{ Pre-RP PSA (ng/ml) } \\
\hline$<10$ & $15(30.6 \%)$ \\
\hline $10-20$ & $15(30.6 \%)$ \\
\hline$>20$ & $19(38.8 \%)$ \\
\hline \multicolumn{2}{|l|}{ Pre-RT PSA (ng/ml) } \\
\hline$<0.2$ & $21(42.9 \%)$ \\
\hline $0.2-2$ & $15(30.6 \%)$ \\
\hline$>2$ & $8(16.3 \%)$ \\
\hline NA & $5(10.2 \%)$ \\
\hline \multicolumn{2}{|l|}{ Pathologic T stage } \\
\hline $\mathrm{T} 2$ & $22(44.9 \%)$ \\
\hline $\mathrm{T} 3 \mathrm{a}$ & $12(24.5 \%)$ \\
\hline $\mathrm{T} 3 \mathrm{~b}$ & $14(28.6 \%)$ \\
\hline $\mathrm{T} 4$ & $1(2.0 \%)$ \\
\hline \multicolumn{2}{|l|}{ Node +} \\
\hline No & $47(95.9 \%)$ \\
\hline N1 & $2(4.1 \%)$ \\
\hline \multicolumn{2}{|l|}{ Extracapsular extension } \\
\hline No & $29(59.2 \%)$ \\
\hline Yes & $20(40.8 \%)$ \\
\hline \multicolumn{2}{|l|}{ Seminal vesicle invasion } \\
\hline No & $34(69.4 \%)$ \\
\hline Yes & $15(30.6 \%)$ \\
\hline \multicolumn{2}{|l|}{ Positive margin } \\
\hline No & $22(44.9 \%)$ \\
\hline Yes & $27(55.1 \%)$ \\
\hline \multicolumn{2}{|l|}{ Perineural invasion } \\
\hline No & $21(42.9 \%)$ \\
\hline Yes & $28(57.1 \%)$ \\
\hline \multicolumn{2}{|l|}{ Lymphovascular permeation } \\
\hline No & $45(91.8 \%)$ \\
\hline Yes & $4(8.2 \%)$ \\
\hline \multicolumn{2}{|l|}{ PSA doubling time } \\
\hline$<6$ months & $13(26.5 \%)$ \\
\hline 6 months & $9(18.4 \%)$ \\
\hline NA (RP to RT<6 months) & $27(55.1 \%)$ \\
\hline
\end{tabular}

Abbreviations: PSA: Prostate-specific antigen; RP: Radical prostatectomy; RT: Radiotherapy; NA: Not available

of $83.1 \%$ and $52.6 \%$, respectively $(p=0.013)$ [Figure 2]. Other factors such as Gleason score, pathologic T stage, positive surgical margin, hormone therapy, and pelvic irradiation were not considered independent prognostic factors.

The toxicity profile is shown in Table 3 , and the grading system for rectal and urinary toxicity is shown in Table 4 . The incidence of chronic rectal toxicity was low, with no grade 3 toxicity reported and grade 2 toxicity found in only 6 patients $(12.2 \%)$. However, long-term urinary toxicity of
Table 2: Multivariate analysis for biochemical progression-free survival

\begin{tabular}{|c|c|c|c|}
\hline Risk factors & $p$ value & Hazard ratio & $95 \% \mathrm{CI}$ \\
\hline Gleason score ( $\leqq 7$ vs. $>7$ ) & 0.356 & \multirow{6}{*}{12.518} & \multirow{6}{*}{$2.316-67.662$} \\
\hline $\begin{array}{l}\text { Pathologic T stage } \\
\text { ( } \leqq \text { pT2 vs. >pT2) }\end{array}$ & 0.321 & & \\
\hline Positive margin (no vs. yes) & 0.197 & & \\
\hline $\begin{array}{l}\text { Pre-RT PSA } \\
(<0.2 \text { vs. } \geqq 0.2 \mathrm{ng} / \mathrm{ml})\end{array}$ & 0.003 & & \\
\hline Hormone therapy (no vs. yes) & 0.335 & & \\
\hline Pelvic irradiation (no vs. yes) & 0.959 & & \\
\hline
\end{tabular}

Abbreviations: CI: Confidence interval; RT: Radiotherapy;

PSA: Prostate-specific antigen

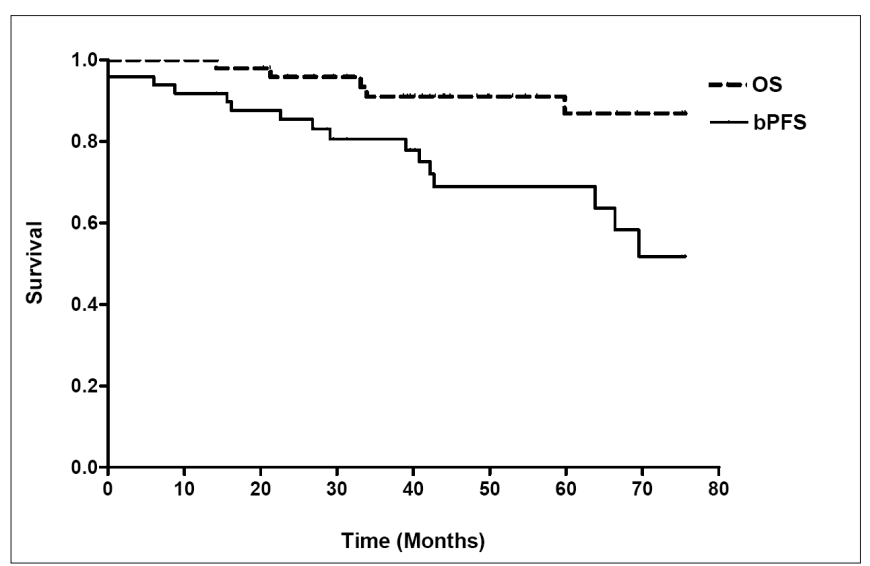

Figure 1: After a median follow-up of 53 months (range 14111 months), the 4-year OS and bPFS for all patients were $91.0 \%$ and $68.9 \%$, respectively (OS, overall survival; bPFS, biochemical progression-free survival)

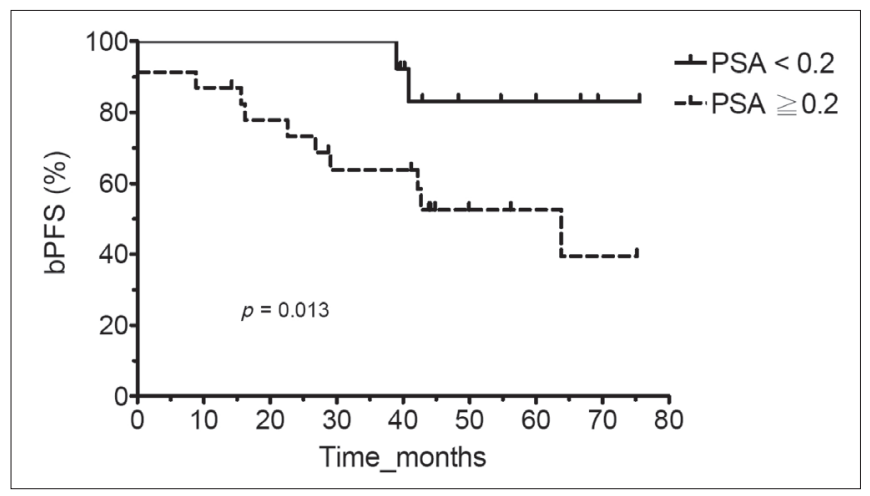

Figure 2: Patients with pre-RT PSA levels of $<0.2 \mathrm{ng} / \mathrm{ml}$ and $\geqq 0.2 \mathrm{ng} / \mathrm{ml}$ had a 4-year bPFS of $83.1 \%$ and $52.6 \%$, respectively $(p=0.013)$ (PSA, prostate-specific antigen; bPFS, biochemical progression-free survival, $\mathrm{RT}$, radiotherapy)

grade 2 or higher was found in 24 patients $(49.0 \%)$. When urinary incontinence was considered separately, long-term pad dependence occurred in $36.7 \%$ of the total population. A relationship between pre-RT urinary incontinence and long-term pad dependence rate was found. Long-term pad dependence rate was $11.8 \%, 22.2 \%$, and $85.7 \%$, respectively, 
for patients with grade 0 , grade 1 , and grade 2 urinary incontinence prior to RT.

\section{DISCUSSION}

This study reports the status of post-RP RT for prostate cancer in Taiwan. Although this is a retrospective study with a limited number of cases, it reveals the poor bPFS of patients with pre-RT PSA $\geqq 0.2 \mathrm{ng} / \mathrm{ml}$. In a study of pathologic features following RP, conducted between 1993 and 2001 in Taiwan, ${ }^{[7]}$ pathological T3-4 disease, Gleason score $\geqq 7$, and positive margin were found in $60 \%, 91 \%$, and $32 \%$ of the patients, respectively, with $56 \%$ of the patients exhibiting a PSA level $>10 \mathrm{ng} / \mathrm{ml}$. Immediate failure was observed in $15 \%$ of the patients and the median time for the

Table 3: Toxicity profile

\begin{tabular}{lc}
\hline Toxicity profile & $(n=49)$ \\
\hline Acute rectal toxicity & $12(24.5 \%)$ \\
Grade 0 & $20(40.8 \%)$ \\
Grade 1 & $17(34.7 \%)$ \\
Grade 2 & \\
Acute urinary toxicity & $2(4.1 \%)$ \\
Grade 0 & $15(30.6 \%)$ \\
Grade 1 & $24(49.0 \%)$ \\
Grade 2 & $8(16.3 \%)$ \\
Grade 3 & \\
Chronic rectal toxicity & $34(69.4 \%)$ \\
Grade 0 & $9(18.4 \%)$ \\
Grade 1 & $6(12.2 \%)$ \\
Grade 2 & \\
Chronic urinary toxicity & $1(2.0 \%)$ \\
Grade 0 & $24(49.0 \%)$ \\
Grade 1 & $16(32.7 \%)$ \\
Grade 2 & $8(16.3 \%)$ \\
Grade 3
\end{tabular}

progression of the disease among the remaining patients was 16 months. These pathological and clinical features suggest that Taiwanese patients receiving RP had more advanced disease and earlier failure. In a recent study of 341 patients from three medical centers in Taiwan, this trend continued with biochemical failure found in $37 \%$ of the patients following a median follow-up of 31 months. ${ }^{[6]}$ These results show a high rate of biochemical failure occurring within a short follow-up period, making it highly likely that patients receiving post-RP RT in Taiwan suffer from more adverse factors, such as larger residual tumor burden or more aggressive tumor behavior, than the patients in western countries.

In the current study, patients with pre-RT PSA level of $<0.2 \mathrm{ng} / \mathrm{ml}$ and $\geqq 0.2 \mathrm{ng} / \mathrm{ml}$ had a 4 -year bPFS of $83.1 \%$ and $52.6 \%$, respectively ( $p=0.013$ ), suggesting that $\mathrm{PSA}<0.2 \mathrm{ng} / \mathrm{ml}$ is an important factor in prognosis. These findings are in agreement with those reported in SWOG 8794, which, after a long-term follow-up, showed a better metastasis-free survival in patients with PSA $<0.2 \mathrm{ng} / \mathrm{ml}$, with the 10-year metastasis-free survival for patients with PSA $<0.2 \mathrm{ng} / \mathrm{ml}$ and $\geqq 0.2 \mathrm{ng} / \mathrm{ml}$ of $73 \%$ and $65 \%$, respectively ${ }^{[10]}$ When facing the clinical dilemma of deciding whether to initiate RT for patients with increased PSA but remaining below biochemical failure, we suggest that RT is preferably administered prior to biochemical failure, if long-term disease control is the goal.

Patients receiving post-RP RT exhibited higher acute and chronic toxicity than those treated primary with RT. Acute grade 3 toxicity was $16.3 \%$ in this study and $7 \%$ in our previous study for patients treated primarily with IMRT. ${ }^{[19]}$ No acute grade 3 toxicity was observed in any patient in this study, treated with prostate implants in conjunction with high-dose-rate (HDR) brachytherapy plus external beam radiotherapy (EBRT) ${ }^{[20]}$ Differences between post-RP RT and primary $\mathrm{RT}$ in chronic complication rates were even greater,

Table 4: The grading system for rectal and urinary toxicities

\begin{tabular}{|c|c|c|c|c|}
\hline \multirow[t]{2}{*}{ Toxicity } & \multicolumn{4}{|c|}{ Grade } \\
\hline & 1 & 2 & 3 & 4 \\
\hline \multicolumn{5}{|l|}{ Rectal } \\
\hline Diarrhea & Increase of $<4$ stools/day & Increase of 4-6 stools/day & Incontinence, hospitalization & Life-threatening \\
\hline Hemorrhage & $\begin{array}{l}\text { Mild, intervention not } \\
\text { indicated }\end{array}$ & $\begin{array}{l}\text { Symptomatic, medical } \\
\text { intervention }\end{array}$ & Transfusion, operative intervention & Life-threatening \\
\hline Proctitis & Rectal discomfort & Medical intervention & Incontinence, operative intervention & Life-threatening \\
\hline \multicolumn{5}{|l|}{ Urinary } \\
\hline Incontinence & $\begin{array}{l}\text { Occasional, pads not } \\
\text { indicated }\end{array}$ & Pads indicated & Intervention indicated & $\begin{array}{l}\text { Organ resection, permanent } \\
\text { urinary diversion }\end{array}$ \\
\hline Hemorrhage & $\begin{array}{l}\text { Microscopic, } \\
\text { intervention not indicated }\end{array}$ & $\begin{array}{l}\text { Gross bleeding, medical } \\
\text { intervention }\end{array}$ & $\begin{array}{l}\text { Transfusion, endoscopic or } \\
\text { operative intervention }\end{array}$ & Life-threatening \\
\hline Stricture & Asymptomatic & $\begin{array}{l}\text { Renal dysfunction, } \\
\text { endoscopic intervention }\end{array}$ & Operative intervention indicated & Life-threatening \\
\hline $\begin{array}{l}\text { Frequency/ } \\
\text { urgency }\end{array}$ & Increase up to $2 \times$ normal & Increase $>2 \times$ normal & $\begin{array}{l}\text { interval less than } 1 \text { hour, catheter } \\
\text { indicated }\end{array}$ & \\
\hline
\end{tabular}


particularly for urinary complications. Forty-nine percent of the patients had grade 2 or higher urinary toxicity, and $36.7 \%$ had urinary incontinence, which eventually became pad-dependent. The rate of $\geqq$ grade 2 urinary complication was found in $14 \%$ of the patients treated primarily by IMRT and $19 \%$ of those treated by HDR brachytherapy plus EBRT. ${ }^{[19,20]}$ Corresponding figures for pad dependence were $3 \%$ and $0 \%$, respectively. The rates of $\geqq$ grade 2 chronic rectal complications were $12.2 \%, 4 \%$, and $6 \%$ for patients treated by post-RP RT and HDR brachytherapy with EBRT and IMRT, respectively. ${ }^{[19,20]}$ The complication rates for post-RP RT in this study are considerably higher than those reported in other studies. The overall complication rate in the post-RP RT group was $23.8 \%$ in the SWOG 8794 trial and $21.9 \%$ in the ARO 96-02 trial. ${ }^{[11,13]}$

The high rate of urinary complication in this study could be attributed to the close relationship between pre-RT and post-RT urinary function. Only $34.7 \%$ of our patients had normal pre-RT urinary function, and $28.6 \%$ had grade 2 urinary toxicity prior to RT. It is well known that the maturation of RP technique involves a steep learning curve. ${ }^{[21,22]}$ Reducing urinary complications is difficult for surgeons in countries with a low incidence of prostate cancer. ${ }^{[23]}$ In this study, PC patients treated by RP were in more advanced stages of the disease, often requiring more radical resection to ensure a negative margin, thereby exacerbating the problem. With regard to the possible impact of RT protocol on chronic urinary toxicity, the given dose and delivery technique remained consistent throughout the study, except for half of the patients receiving pelvic irradiation. However, studies on radical RT have indicated that pelvic irradiation is associated with an increase in rectal, but not urinary toxicity. ${ }^{[24,25]}$

The retrospective nature and limited number of cases in this study impose considerable limitations on the applicability of these findings. Although all of the patients were treated according to the same principles, the limited number of cases made it difficult to perform analysis based on adjuvant or salvage RT. Nonetheless, this study still showed that for patients with increasing PSA levels following RP, local RT should be administered prior to biochemical failure (PSA $\geqq 0.2 \mathrm{ng} / \mathrm{ml}$ ), to ensure good bPFS. However, post-RP RT involves considerable urinary toxicity, often leading to long-term urinary incontinence.

\section{REFERENCES}

1. Bureau of health promotion DoH, The executive Yuan. Cancer Registry Annual Report, 2007.

2. Ferlay J, Autier P, Boniol M, Heanue M, Colombet M, Boyle P. Estimates of the cancer incidence and mortality in Europe in 2006. Ann Oncol 2007;18:581-92.

3. Jemal A, Siegel R, Xu J, Ward E. Cancer statistics, 2010. CA Cancer J Clin 2010;60:277-300.
4. Wu TT, Huang JK. Annual changes in the clinical features of prostatic adenocarcinoma in Taiwan. BJU Int 2001;87:57-60.

5. Pu YS. Prostate cancer in Taiwan: Epidemiology and risk factors. Int J Androl 2000;23 Suppl 2:34-6.

6. Huang SP, Huang CY, Liu CC, Yu CC, Pu YS, Chueh SC, et al. Clinical outcome of Taiwanese men with clinically localized prostate cancer post-radical prostatectomy: A comparison with other ethnic groups. Aging Male 2010;13:10-7.

7. Chuang AY, Chang SJ, Horng CF, Tsou MH. Study of prostate cancer pathologic features in Chinese populations. Urology 2007;69:915-20.

8. Pu YS, Chiang HS, Lin CC, Huang CY, Huang KH, Chen J. Changing trends of prostate cancer in Asia. Aging Male 2004;7:120-32.

9. Arai Y, Kanamaru H, Moroi S, Ishitoya S, Okubo K, Suzuki Y, et al. Radical prostatectomy for clinically localized prostate cancer: Local tumor extension and prognosis. Int J Urol 1996;3:373-8.

10. Thompson IM, Tangen CM, Paradelo J, Lucia MS, Miller G, Troyer D, et al. Adjuvant radiotherapy for pathological T3N0M0 prostate cancer significantly reduces risk of metastases and improves survival: Long-term followup of a randomized clinical trial. J Urol 2009;181:956-62.

11. Thompson IM, Jr., Tangen CM, Paradelo J, Lucia MS, Miller G, Troyer D, et al. Adjuvant radiotherapy for pathologically advanced prostate cancer: A randomized clinical trial. JAMA 2006;296:2329-35.

12. Bolla M, van Poppel H, Collette L, van Cangh P, Vekemans K, Da Pozzo L, et al. Postoperative radiotherapy after radical prostatectomy: A randomised controlled trial (EORTC trial 22911). Lancet 2005;366:572-8.

13. Wiegel T, Bottke D, Steiner U, Siegmann A, Golz R, Storkel S, et al. Phase III postoperative adjuvant radiotherapy after radical prostatectomy compared with radical prostatectomy alone in pT3 prostate cancer with postoperative undetectable prostate-specific antigen: ARO 96-02/AUO AP 09/95. J Clin Oncol 2009;27:2924-30.

14. Stephenson AJ, Scardino PT, Kattan MW, Pisansky TM, Slawin KM, Klein EA, et al. Predicting the outcome of salvage radiation therapy for recurrent prostate cancer after radical prostatectomy. J Clin Oncol 2007;25:2035-41.

15. Corn BW, Winter K, Pilepich MV. Does androgen suppression enhance the efficacy of postoperative irradiation? A secondary analysis of RTOG 85-31. Radiation Therapy Oncology Group. Urology 1999;54:495-502.

16. Cheung R, Kamat AM, de Crevoisier R, Allen PK, Lee AK, Tucker SL, et al. Outcome of salvage radiotherapy for biochemical failure after radical prostatectomy with or without hormonal therapy. Int J Radiat Oncol Biol Phys 2005;63:134-40.

17. King CR, Presti JC, Jr., Gill H, Brooks J, Hancock SL. Radiotherapy after radical prostatectomy: Does transient androgen suppression improve outcomes? Int J Radiat Oncol Biol Phys 2004;59:341-7.

18. Roach M, $3^{\text {rd }}$, Marquez C, Yuo HS, Narayan P, Coleman L, Nseyo UO, et al. Predicting the risk of lymph node involvement using the pre-treatment prostate specific antigen and Gleason score in men with clinically localized prostate cancer. Int J Radiat Oncol Biol Phys 1994;28:33-7.

19. Fan KH, Chen YC, Chuang CK, Hsieh ML, Hong JH. Preliminary treatment results of intensity-modulated radiotherapy for prostate cancer. Chang Gung Med J 2006;29:313-24.

20. Chen YC, Chuang CK, Hsieh ML, Chen WC, Fan KH, Yeh CY, 
et al. High-dose-rate brachytherapy plus external beam radiotherapy for T1 to T3 prostate cancer: An experience in Taiwan. Urology 2007;70:101-5.

21. Eden CG, Neill MG, Louie-Johnsun MW. The first 1000 cases of laparoscopic radical prostatectomy in the UK: Evidence of multiple 'learning curves'. BJU Int 2009;103:1224-30.

22. Secin FP, Savage C, Abbou C, de La Taille A, Salomon L, Rassweiler J, et al. The learning curve for laparoscopic radical prostatectomy: An international multicenter study. J Urol 2010;184:2291-6.

23. Arai Y, Egawa S, Terachi T, Suzuki K, Gotoh M, Kawakita M, et al. Morbidity of laparoscopic radical prostatectomy: Summary of early multi-institutional experience in Japan. Int J Urol 2003;10:430-4.

24. Aizer AA, Yu JB, McKeon AM, Decker RH, Colberg JW, Peschel RE. Whole pelvic radiotherapy versus prostate only radiotherapy in the management of locally advanced or aggressive prostate adenocarcinoma. Int J Radiat Oncol Biol Phys 2009;75:1344-9.

25. Roach M, $3^{\text {rd }}$, DeSilvio M, Valicenti R, Grignon D, Asbell SO, Lawton C, et al. Whole-pelvis, "mini-pelvis," or prostate-only external beam radiotherapy after neoadjuvant and concurrent hormonal therapy in patients treated in the Radiation Therapy Oncology Group 9413 trial. Int J Radiat Oncol Biol Phys 2006;66:647-53. 